\title{
Online Learning: Challenges for Education in Rural and Remote Areas
}

\author{
Namita Kumari Das ${ }^{1}$, Snehaprava Sahoo' ${ }^{2}$ Lopamudra Pati ${ }^{3}$ \\ Asst Prof in Psychology, Dhenkanal Autonomous College ${ }^{1}$ \\ G.M University, Sambalpur² \\ Utkal University, Bhubaneswar ${ }^{3}$
}

\begin{abstract}
Educational institutes across India have been closed since mid-March 2020 due to the outbreak of the COVID-19 pandemic. Schools and colleges in rural, remote areas of India are experiencing unprecedented challenges due to the closure of institutions. Against this backdrop, the present paper explored the challenges of online learning in rural areas for all stakeholders. This qualitative investigation was conducted on two students, two parents, and two teachers in rural areas. The uniqueness of the study is that it analysed the challenges of online learning from the perspective of students, teachers, and parents. It is found from the study that online teaching-learning is challenging due to multiple factors such as lack of technical gadgets, poor network connectivity, and electricity problems. Lack of previous experience in online teaching is a major shortcoming for teachers. Parental literacy and student interest are other hindrances. Stress has been experienced by parents, students, and teachers due to the transition from traditional to online learning.
\end{abstract}

KEYWORDS COVID-19. Online Learning. Rural Areas. Unprecedented Challenges

\section{INTRODUCTION}

The global spread of the COVID-19 pandemic has affected almost all nations of the world and has triggered an array of public health responses. The pandemic forced the closure of all kinds of organizations across the world. Closures of all sorts of educational institutions was a significant physical distancing measure adopted by the government of different countries to curb the spread of this contagious disease. Distance education, educational applications, and platforms can be used by schools and teachers to be in touch with students and curb the interruption of education[1]. Online education was included in the earliest decade of this century in the Indian education system as a method of distance education. This method of learning requires access to digital devices along with Internet connectivity. Video conferencing, PDFs, educational videos, and audio clipping are the tools, which are used in this method. Various apps like Zoom, Google Meet, Jio Meet, etc. are used for video conferencing. WhatsApp and Telegram are used for sharing study materials with the students.

During the lockdown, all class promotion examinations in schools of Odisha were suspended and students were promoted to higher class based on their term marks. The new session also started in April 2020 to avoid academic delay. The School and Mass Education Department of the Government of Odisha adopted an online mode of instruction to resume the teaching-learning process. This instruction became a puff to rural students as they are habituated with a conventional classroom setup, where a teacher is physically present to guide students and monitor their learning directly. Online learning is new to students in rural areas.

\section{Problem}

With the decision of the government to resume classes to engage students, suddenly traditional education changed to an online mode of instruction. This alteration from conventional to digital changed the educational system in ways and the effects are yet to be determined [2]. Teachers and students are required to find ways to connect and face the challenges of change from familiar to a new way of teaching-learning. Whether it's distance or virtual learning, teachers are challenged to reach virtually all of their students [3]. Before the pandemic, online learning was there but all teachers are not familiar with the technology. Being restricted at home, challenged to quickly learn new technologies, many teachers experienced the single most distressing episode of the current age [4]. The Students in social isolation and seclusion had to develop new skills desirable for e-learning [5].

Online education is also likely to broaden the learning gap between children from lower-income and higher-income families [6]. Children from below poverty line households live in conditions that are not conducive to online learning. The biggest hurdles to moving to online education in India have been insufficient digital gadgets for students and a lack of internet connection at home owing to poverty. Children from lower-income households are struggling to complete online homework because of the inconducive atmosphere at home [6]. Recently news came that a father committed 


\section{International Advanced Research Journal in Science, Engineering and Technology}

Vol. 8, Issue 7, July 2021

\section{DOI: 10.17148/IARJSET.2021.8712}

suicide, as he could not provide smartphones to his children for study [7]. In another place, a family that had to sell their cow, the only source of income for the family, to buy a smartphone, became a hot topic [8]. Upset about not having a smartphone to use for online classes, a 17-year-old girl studying in class 11, from Punjab committed suicide [9]. Away from school and friends students find online classes boring [10]. The sudden interruptions to education owing to the COVID-19 necessitated the study and document the major changes in teaching practices and teachers' responsibilities [11].

\section{Rationale}

To translate the power of IT into an extended learning opportunity for all is the ethos of online learning. The Government of India has launched the National Mission on Education through ICT (NMEICT) to democratise the opportunity of online learning. To promote digital education, various initiatives have been taken such as SWAYAM, SWAYAM Prabha, ShodhGanga INFLIBNET, National Digital Library, and National Academic Depository by the Ministry of Human Resources Development. Besides these platforms, the MHRD has developed the Diksha App and channels and numerous initiatives for the development of online learning in India. As there were no other alternatives, both the central as well as state governments ordered the online learning method during lockdown to resume the teaching-learning process.

The study is based on this fundamental idea, which views that the people who face the challenge can come out with an effective plan to solve their problems. To this end, the participants in this study were rural students, parents, and teachers who were facing difficulty with online teaching and learning. To the researchers' knowledge, no such studies have taken place to investigate the challenges of online learning in rural areas following the COVID-19 school closure. This study investigates the impact of online learning due to COVID-19 induced school closure on teachers, students, and parents who belong to rural areas of the Dhenkanal district in Odisha.

Thus, the following research questions were framed:

What changes in work did the teacher experience, and what are the challenges he/she faces to provide online instruction to the students?

What are the challenges students face for and during online instruction?

How did the parents perceive the online teaching experience and what are the challenges?

The research questions addressed important research gaps in this field by involving major stakeholders such as students, teachers, and parents.

\section{Objectives}

The objective of this study was to illustrate the experiences of school teachers, students, and parents adopting online instruction during the COVID-19 lockdown.

The study intends to understand the challenges faced by teachers, students, and parents to adopt the online teachinglearning process in the context of the closure of schools due to COVID-19.

\section{REVIEW OF LITERATURE}

The pandemic in various ways affected the lives of people in terms of occupation, education, communications, financial resources, and health. For the well-being of society, governments throughout the world closed the educational institutions. This unexpected and exceptional interruption in social life and the educational system altered the work of many teachers abruptly, and in several aspects [12]. A study exploring the critical challenges and factors influencing the e-learning system usage during the COVID19 pandemic found that technical factors were one of the significant factors that influenced the practice of e-learning systems[13].

A study in South Africa and found that many rural learners are deprived of the online teaching-learning process, owing to a lack of digital gadgets to connect to the Internet, the learning management system, and software[14]. Using both qualitative and quantitative data, the professional life of a secondary school teacher was examined who had continued teaching his students in rural Alaska (United States) by online mode during COVID-19. It was found from the study that the teacher experienced extra workload and viewed that the online education should be inclusive and carefully designed [15].

In developing countries, the e-learning process might be hindered by technological knowledge, education and literacy background, and socio-economic problems of the people [16]. In Southeast Asia, a large section of the population neither possess electronic devices nor have access to the Internet. Even people with access to the internet, experience inconvenience because of several factors including the inconsistency of internet speeds in different regions. The urban population often enjoys significantly faster internet compared to those living in less developed areas [17]. Internet connectivity and access to digital gadgets remain a persistent equity question, particularly in rural areas $[18,19]$.

A study conducted in Nepal shows that many students got disturbed during their online class because of electricity problems (63.2\%), and because of Internet problems (63.6\%). Similarly, about half of the teachers got troubled by their 


\section{International Advanced Research Journal in Science, Engineering and Technology}

Vol. 8, Issue 7, July 2021

\section{DOI: 10.17148/IARJSET.2021.8712}

online teaching because of the power problems (42.3\%), and because of Internet problems (48.1\%) [20]. News that children are sitting on the trees, near any high places or river banks for attending classes is seen through electronic media and social media platforms in Odisha [21].

\section{Design}

\section{METHODOLOGY}

This descriptive and explanatory qualitative study focuses on the perception of changes in the instructional practices from traditional classroom practices to online mode by students, teachers, and parents. Although the qualitative study has limits [22], the strong point of this method was that it considers the perspective of all active participants, that is, students, teachers, and parents. The study explored the teacher's voice in-depth, student's attitudes and views, and parent's problems using varied methods of data collection.

Data was collected by direct and participant observations in their workspace, semi-structured interviews, open-ended questions, and telephonic conversation. The researchers had a thorough knowledge of the teacher's workload and conditions of working. They were aware of rural parents' and students' problems regarding technology know-how before the change to online education. Therefore, they maintained vigilance throughout the study to explore the impact of school closure and the shift to online instruction as perceived by the respondent teachers, students, and parents.

\section{Participants}

The participants of this study included two teachers, one male and one female teacher, two students, one boy, and one girl, and two guardians, one male, and one female. All the participants of the study belong to a rural government school in the Dhenkanal district of Odisha. The teachers have more than fifteen years of experience in the schools where they are posted. Owing to their long residency at the school, they had thorough knowledge about the students and the area where the school is located.

\section{Data Collection}

Descriptive data about the teacher's experiences, student's perceptions, and parent's attitudes, and challenges faced by all the participants while adopting online learning were collected over two weeks from multiple sources. The semistructured interview questions that included both open-ended and closed questions and daily discussion over the topic in social media were conducted and recorded. Interviews and discussions focused on the overall respondent observation of the effectiveness of an online learning model, the problems and challenges of online learning, and suggestions from all the participants about its implementation in the future as an alternative model. Open-ended questions were designed with a focus on content, clarity, and sequencing. All the discussions were held through a personal interview maintaining physical distance, via a telephonic conversation, and WhatsApp chats. Pseudo names have been used to keep the identity of participants secret.

Questions for the teachers were:

What are the challenges you face because of school closure and transition from classroom learning to online learning? How did you engage your students and what is your perception of student participation?

Questions for the students were:

What is your experience with online learning? Do you find online learning interesting?

Do you face any problems with online learning?

Questions for the parents were:

What are the challenges you face because of school closure and transition from classroom learning to online learning? How did you perceive authority or the role of teachers to support you in online education?

\section{RESULTS}

Responding to the first question Teacher X said, "This is a serious challenge to take online classes owing to no or limited network. Sometimes I have to go outside of my home for network issues. One day while I was busy taking a class on the roof of my house, a group of monkeys suddenly jumped from my neighbour's roof to mine for which I had to stop class and escape. Online learning is suitable in urban places where there is no network problem. All students are not able to benefit from online learning, as they are used to traditional learning. The students in my school need constant support and guidance from teachers, as their parents are unable to guide them. I feel sorry for them and feel stressed and guilty, as students are not fairly treated under this system."

Teacher Y also expressed her concern regarding the problems of online learning. "I bought a smartphone after the direction from authority to take online classes. It took me days to learn the internet application. As per the order of authority, we teachers formed a WhatsApp group with students. But we could add only a few students, as they did not have smartphones. All the teachers of my school went door to door to distribute the course books and other study materials. Most of the people are daily labourers, auto-rickshaw drivers, and vegetable vendors and engaged in other occupations. They cannot afford to buy a smartphone, and Internet connectivity and data usage is another issue."

Both the teachers expressed their concern about student engagement and participation. More or less their voice is the same about student participation. "Although in one class there are about forty students, only eight to ten students ask 


\section{International Advanced Research Journal in Science, Engineering and Technology}

Vol. 8, Issue 7, July 2021

\section{DOI: 10.17148/IARJSET.2021.8712}

their doubts and submit assignments. Some do not have a device, some suffer from poor connectivity and some do not have guardians to guide them. We have informed the students and their guardians about the Diksha channel and asked the students to watch the channel as per the programme. We could not visit their homes frequently due to fear of contamination."

One guardian (male) said, "I am an auto rickshaw driver. I have a mobile phone but that remains with me for the whole day, as people call me to reserve drives to the hospital or station. Due to the lockdown, I have very small or no income. I am not investing a single rupee in the education of my children. The government is providing everything, like dresses, books, mid-day meals, and a cycle free for the education of my child. I cannot buy a new phone though I wish to provide one to my child."

"I am a tailor and my husband has a roadside tiny tea-biscuit shop. We have two children, one studying in college and another in high school. We have a smartphone. The elder child attends online classes with this phone. We cannot provide two phones. The school-going child faces problems attending online classes, as the older child seldom gives the phone to him. The school-going child views the audio-video clip sent by the teachers in the WhatsApp group shared by his teachers."

Both the students and guardians expressed satisfaction over the role of teachers during the lockdown. Replying to the second question one guardian said, "Teachers of the school visited our house to distribute the books for the new session. They asked me to buy a mobile phone or a computer with an internet facility. They also informed us about the Diksha channel on television. Our child is also unable to fully attend the channel during class because of the electricity power cut. Teachers respond when my child calls for any doubt clarification. But I am sure, this is not a solution for all students."

To know the response of students who possess smartphones and computers with network connections, the investigators recorded the reaction of two students about their experience with online learning. Both students retorted that they have smartphones but the network is not always available. Though it is very interesting for them to learn online, the frequent interruptions create disappointment. "Electricity power problems always persist in our area. Sometimes I also lose interest in studying alone. In school, it is very interesting to study with friends. Doubt clearing is very easy also, as we can ask friends and teachers whenever there is difficulty in understanding the concepts."

\section{DISCUSSION}

This study was carried out in the Dhenkanal district of Odisha in 2020 and pointed out the challenges of online education in rural areas. In most of the schools, there are no facilities for online classes till now, and teachers are still getting training on how to conduct such classes. In short, the benefits of conducting online classes are not that great in rural and remote areas. Even though telecommunication and the internet are available in grass root areas of India, not every place has a strong network and Internet services. So, students do not get chances to attend classes or take examinations. When the lockdown started, all the educational institutions got closed all of a sudden. Students become carefree and fickle, as there were no regular classes or tuitions for them. Lack of teacher-student, student-student interaction, and blackboard method of teaching and learning affected the quality of education given to the students. Doubt-clearance becomes very difficult in the online method.

A chaotic environment at home, family fights and, lack of meals also affect the mental state of the students and prevent them from studying. Many people in rural areas live below the poverty lines. So, when having proper meals is difficult for these people, the families can't afford such expensive tools for the education of their children. As most of the parents have lack education, they face immense difficulties in guiding their children. They feel stressed and depressed, as they could not provide the basic necessity for online education for their children. The challenges of online education found by this study confirms the result of earlier such studies conducted by Almaiah (2020), Dube (2020), Babu and Reddy (2015), McLaren (2003) Azano and Stewart (2015), and Subedi et al. (2020)

After the students, if anyone is getting affected worst, they are the teachers of rural schools. In rural schools, the teachers and students are habituated with the traditional teaching-learning method. This study found that teachers did not have proper knowledge about online classes and had not been given any training. As the teachers are middle-aged or old, they usually do not know how to conduct online classes via smartphones or laptops. They are seen taking help from their children or grandchildren. Due to online classes, some teachers faced lower self-esteem, productivity in teaching, and their motivation level decreased. Besides teaching, the teachers were also engaged in various works like distributing books, re-admission of the students and some had to take care of the quarantine centres situated in their schools. Teachers reported being stressed due to all these challenges. The findings of the present study come in line with earlier studies conducted by Baired (2020), Fagell (2020), and Kaden (2020). 


\section{International Advanced Research Journal in Science, Engineering and Technology}

Vol. 8, Issue 7, July 2021

\section{DOI: 10.17148/IARJSET.2021.8712 CONCLUSION \& RECOMMENDATIONS}

Before the onset of the COVID-19 outbreak and lockdown, the education system in rural India was not qualitative even after the implementation of numerous welfare schemes. Through the research, it emerged that despite online learning seems to be one of the possible ways of learning in the COVID-19 period but the application of technology is troubled by several factors. Online education for school children is challenging owing to multiple problems like unavailability of the network, lack of resources to buy the necessary gadget and data, power problem, inadequate knowledge, not conducive home climate, and lack of direct contact between student and teacher. Although the study has limitations like small sample size, it has approached the issue intensively by including all the stakeholders.

The findings of the study are significant for the implementation of online education. It is suggested here that proper training should be provided to both the students and teachers. Caring and training for teachers are some conditions of recovery from the catastrophic situation and sustainable education practice of the future. Smartphones and other necessary extensions should be provided to economically poor students. If possible, schools and other educational institutions should be reopened with adherence to social distancing and proper precautions to prevent the individuals from getting affected.

\section{REFERENCES}

1. UNESCO (2020). School Closures Caused by Coronavirus (Covid-19). From<https://en.unesco.org/covid19/educationresponse.> (Retrieved on 28 April 2020).

2. Van Lancker W \& Parolin Z (2020) COVID-19, school closures, and child poverty: A social crisis in the making. Lancet Public Health, 5: e-235. 3. Merrill S (2020). Teaching through a Pandemic: A Mindset for This Moment. From <https://www. edutopia.org/article/teaching-throughpandemic-mindset-moment> (Retrieved on 20 August 2020).

4. Baired K (2020). Caring for Educators is the First Step in Serving Students. From <https://thejournal.com/articles/2020/05/19/caring-foreducators-is-the-first-step-in serving-students.aspx $>$ (Retrieved on 12 January 2021).

5. Brooks SK, Webster RK, Smith LE, Woodland, L, Wessely S, Greenberg N, Rubin GJ (2020). The psychological impact of quarantine and how to reduce it: Rapid review of the evidence. Lancet, 395: 912-920.

6. Reich J, Buttimer CJ, Fang A, Hillaire G, Hirsch K, Larke LR, Slama R (2020). Remote learning guidance from state education agencies during the covid-19 pandemic: A first look. EdArXiv. https://doi.org/10.35542/osf.io/437e2.

7. Barman PD (2020). HT Media. Hindustan Times. 2 July From<https://m-hindustantimes-com.cdn.ampproject.org/v/s/m.hindustantimes.com/indianews/tripura-man-ends-life-after-failing-to-buy-smartphone-for-daughter-s-online-classes/story > (Retrieved on 15 August 2020).

8. Sood R (2020). Man Sells Cow to Buy Smartphone for Online Studies of His Children. From<https://www.tribuneindia.com/news/himachal/mansells-cow-to-buy-smartphone-for-online-studies-of-his-children-116524> (Retrieved on 20 August 2020).

9. Ghazali M (2020). June. From < No Smartphone For Online Classes, Punjab Girl Allegedly Commits Suicide NDTV> (Retrieved on 15 August $\underline{2020)}$.

10. Sudevan P 2020 Why E-Learning Isn't a Sustainable Solution to the COVID-19 Education Crisis in India From<https://www.thehindu.com/scitech/technology/why-elearning-is-not-a-sustainable-solution-to-the-covid19-education-crisis-in-india/article31560007.ece> (Retrieved on 8 August 2020).

11. Yang X (2020). Teachers' perceptions of large-scale online teaching as an epidemic prevention and control strategy in China. ECNU Review of Education, 3(4): 739-744. https://doi.org/10.1177/2096531120922244

12. Fagell PL (2020). Career confidential: Teacher wonders how to help students during coronavirus shutdown. Phi Delta Kappan, $101:$ 67-68.

13. Almaiah MA, Al-Khasawneh A, Althunibat A (2020). Exploring the critical challenges and factors influencing the E-learning system usage during the COVID-19 pandemic. Educ Inf Technol, 1-20. doi:10.1007/s10639-020-10219-y.

14. Dube B (2020). Rural online learning in the context of COVID-19 in South Africa: Evoking an Inclusive Education Approach. Multidisciplinary Journal of Educational Research, 10(2): 135-157. DOI: 10.4471/remie.2020.5607

15. Kaden U (2020). COVID-19 school closure-related changes to the professional life of a K-12 teacher. Educ Sci, 10: 165.

16. Babu Naresh, Reddy Bhanu (2015). Challenges and opportunity of e-learning in developed and developing countries-A review. International Journal of Emerging Research in Management and Technology, 4: 2278-9359.

17. Jally N (2020). Lack of Internet Access in South-East Asia Poses Challenges for Students to Study Online Amid COVID-19 Pandemic. From $<$ https://theconversation.com/lack-of-internet-access-in-southeast-asia-poses-challenges-for-students-to-study-online-amid-covid-19-pandemic$133787>$ (Retrieved on 22 November 2020).

18. McLaren P (2003). Life in Schools: An Introduction to Critical Pedagogy in the Foundations of Education. $4^{\text {th }}$ Edition. Albany, NY, USA: Allyn \& Bacon.

19. Azano A P \& Stewart T T (2015). Exploring place and practicing justice: Preparing preservice teachers for success in rural schools. J Res Rural Educ, 30: 1-12.

20. Subedi S, Nayaju S, Subedi S et al. (2020). Impact of e-learning during COVID-19 pandemic among nursing students and teachers of Nepal. International Journal of Science \& Health Care Research, 5(3): 68-76.

21. Sambad English Bureau 2020. Just $15 \mathrm{Km}$ Away From Smart City Bhubaneswar Students Perch on Trees For Online Classes. From<https://sambadenglish.com/just-15-km-from-smart-city-bhubaneswar-students-perch-on-trees-for-online-classes/> (Retrieved on 20 August 2020).

22. Miles MB, Huberman AM, Saldana J 2014. Qualitative Data Analysis: A Methods Sourcebook. Thousand Oaks, CA, USA: Sage. 